\title{
Phenotypic and genotypic characterization of carbapenem-resistant Acinetobacter baumannii isolates from Egypt
}

\author{
Alaa Abouelfetouh* (D), Aisha S. Torky and Elsayed Aboulmagd
}

\begin{abstract}
Background: Antibiotic use is largely under-regulated in Egypt leading to the emergence of resistant isolates. Carbapenems are last resort agents to treat Acinetobacter baumannii infections resistant to other classes of antibiotics. However, carbapenem-resistant isolates are emerging at an alarming rate. This study aimed at phenotypically and molecularly characterizing seventy four carbapenem-unsusceptible A. baumannii isolates from Egypt to detect the different enzymes responsible for carbapenem resistance.

Methods: Carbapenemase production was assessed by a number of phenotypic methods: modified Hodge test $(\mathrm{MHT})$, carbapenem inactivation method (CIM), combined disc test (CDT), CarbAcineto NP test and boronic acid disc test. Polymerase chain reaction (PCR) was used to screen the isolates for the presence of some genes responsible for resistance to carbapenems, as well as some insertion sequences.

Results: PCR amplification of class D carbapenemases revealed the prevalence of bla $a_{O X A-51}$ and $b / a_{O X A-23}$ in $100 \%$ of the isolates and of bla $a_{O X A-58}$ in only one isolate (1.4\%). bla $a_{V M}$ and bla $a_{N D M-1}$ belonging to class B metallo- $\beta$-lactamases were present in 100 and $12.1 \%$ of the isolates, respectively. The prevalence of ISAba1, ISAba2 and ISAba3 was 100, 2.7 and $4.1 \%$, respectively. None of the tested isolates carried bla $a_{O X A-40}, b / a_{I M P}, b / a_{S I M}, b / a_{S P M}, b / a_{G I M}$ or the class $A$

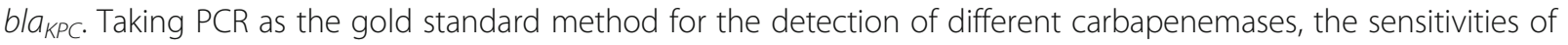
the MHT, CIM, CDT, CarbAcineto NP test and boronic acid disc/imipenem or meropenem test for this particular collection of isolates were $78.4,68.9,79.7,95.9$, and $56.8 \%$ or $70.3 \%$, respectively.

Conclusions: The widespread detection of carbapenem-resistant A. baumannii (CR-AB) has become a real threat to the efficacy of treatment regimens. Among the studied cohort of CR-AB clinical isolates, bla OXA-51, bla OXA-23 and $b a_{V I M}$ were the most prevalent, followed by $b a_{N D M-1}$ and bla $a_{O X-58}$. The genotypic detection of carbapenemases among CR-AB clinical isolates using PCR was most conclusive, followed closely by the phenotypic testing using CarbAcineto NP test.
\end{abstract}

Keywords: Acinetobacter baumannii, Carbapenemase prevalence, CarbAcineto NP test, bla OXA-51, bla OXA-23, bla $a_{N D M}$

\section{Background}

Acinetobacter baumannii has become a life threatening pathogen [1]. It causes nosocomial infections worldwide, including skin and soft tissue infections, wound and bloodstream infections, urinary tract infections, meningitis and ventilator-associated pneumonia which is the most common and fatal infection caused by A. baumannii [2-6]. These infections are particularly dangerous

\footnotetext{
* Correspondence: Alaa.abouelfetouh@pharmacy.alexu.edu.eg Department of Microbiology and Immunology, Faculty of Pharmacy, Alexandria University, 1 Khartoum Sq., Azarita, Alexandria 21521, Egypt
}

because of the pathogen's ability to resist the action of most currently available antibacterial agents [7], making A. baumannii one of the most dangerous ESKAPE organisms [Enterococcus faecium, Staphylococcus aureus, Klebsiella pneumoniae, A. baumannii, Pseudomonas aeruginosa and Enterobacter species] [8, 9]. Moreover, the number of community-acquired $A$. baumannii infections such as bacteraemia, pneumonia, meningitis and endocarditis has been progressively increasing in the last few decades $[10,11]$.

(c) The Author(s). 2019 Open Access This article is distributed under the terms of the Creative Commons Attribution 4.0 International License (http://creativecommons.org/licenses/by/4.0/), which permits unrestricted use, distribution, and reproduction in any medium, provided you give appropriate credit to the original author(s) and the source, provide a link to the Creative Commons license, and indicate if changes were made. The Creative Commons Public Domain Dedication waiver (http://creativecommons.org/publicdomain/zero/1.0/) applies to the data made available in this article, unless otherwise stated. 
The unnecessary and extensive use of antibiotics in healthcare settings led to the acquisition of novel genetic determinants for antibiotic resistance. These, added to the intrinsic resistance of $A$. baumannii to many antibiotics, resulted in the development of multidrug-resistant, extensively drug-resistant and even pan drug-resistant $\mathrm{A}$. baumannii strains, mainly in intensive care settings [12-14], limiting the options available to treat such infections to a few agents such as the carbapenems [15]. Yet, A. baumannii has also developed resistance to carbapenems and carbapenem-resistant $A$. baumannii (CR-AB) isolates have been reported all over the world, challenging modern day medicine [16].

Carbapenem resistance among A. baumannii strains occurs due to the loss or modification of porins or in some rare cases due to modification of penicillin binding proteins [17]. However, the main resistance mechanism is the production of $\beta$-lactamase enzymes [18-20]. Four molecular $\beta$-lactamase classes (A, B, C and D) have been detected in A. baumannii $[21,22]$. Only a few $K$. pneumoniae carbapenemase (KPC) type enzymes from class A $\beta$-lactamases have an effect on carbapenems contrary to classes B and D which act efficiently on carbapenems [23]. Class B $\beta$-lactamases are metallo- $\beta$-lactamases (MBL) that need zinc ions for their catalytic activity [23]. Four examples of MBL are known in A. baumannii, including New Delhi Metallo- $\beta$-lactamase (NDM), Imipenemase (IMP), Seoul Imipenemase (SIM) and Verona integron-encoded metallo- $\beta$-lactamase (VIM) [24, 25]. Two variants of NDM have been reported (NDM-1 and NDM-2). The two variants have been reported in Egyptian A. baumannii clinical isolates. The first variant (NDM-1) was detected in a repatriated Czech citizen after being admitted to a hospital in Egypt in 2011, it is not clear whether the patient was colonized or infected [26]. The second variant (NDM-2) was isolated in Germany from a venous line catheter placed for a child while being hospitalized in Egypt [27]. Regarding Class D $\beta$-lactamases, also named oxacillinases (OXAs) for their activity on oxacillin [28], there are six subgroups: the naturally occurring, chromosomal and intrinsic OXA-51 and the acquired OXA-23-like, OXA-58-like, OXA-24/40-like, OXA-235-like and OXA-143-like $\beta$ lactamases [29]. The presence of certain insertion sequences upstream of carbapenem-hydrolyzing class $D \beta$ lactamase (CHDLs) genes leads to their over-expression, conferring carbapenem resistance [30].

Detection of the carbapenemases is crucial to determine the severity of the problem and to direct the application of antimicrobial stewardship guidelines to limit further evolution of carbapenem-resistant variants among $A$. baumannii isolates. The current study is reporting the prevalence of certain carbapenemases among CR-AB isolates from Alexandria, Egypt, comparing the different phenotypic and molecular techniques to detect these enzymes among $\mathrm{CR}-\mathrm{AB}$ isolates in an Egyptian setting.

\section{Methods \\ Bacterial isolates}

Seventy four CR-AB isolates, from different clinical specimens: broncho-alveolar lavage (BAL) $(n=43)$, urine $(n=7)$, blood $(n=6)$, sputum $(n=6)$, pus $(n=4)$, miniBAL $(n=4)$, wound $(n=2)$ and tissue $(n=2)$, collected from the medical microbiology lab at Alexandria Main University Hospital in $2010(n=39)$ and $2015(n=35)$ were included in the study. The isolates were mostly collected during fall and winter 2010 and spring 2015, were non-duplicate and came from different wards in the hospital. The isolates were identified by phenotypic and growth based methods, including colony morphology, aerobic growth on MacConkey's agar at $44{ }^{\circ} \mathrm{C}$ [31] and Vitek system (Biomerieux, UK). The identity was confirmed by molecular methods, namely the polymerase chain reaction (PCR) amplification of bla OXA-51 gene [32] as well as Matrix Assisted Laser Desorption Ionization - Time of Flight Mass Spectrometry (MALDITOF MS) (Bruker Daltonik, USA) [33, 34].

Carbapenem susceptibility of the clinical isolates was checked by the standard disc diffusion technique on Müller-Hinton agar using imipenem and meropenem discs (Oxoid, Basingstoke, United Kingdom), according to CLSI 2018 guidelines [35]. The minimum inhibitory concentration (MIC) of imipenem (Merck Sharp \& Dohme B.V., The Netherlands) and meropenem (Astrazeneca, United Kingdom) were determined against the tested clinical isolates using agar dilution method to confirm carbapenem resistance, and the results were interpreted according to CLSI 2018 guidelines (data not shown) [35].

\section{Phenotypic detection of carbapenemases Modified Hodge test (MHT)}

MHT was performed as descried before [36]. One to ten dilution of 0.5 McFarland suspension of the carbapenemsusceptible E. coli ATCC 8739 was aseptically swabbed onto a sterile Müller-Hinton agar plate. A meropenem disc $(10 \mu \mathrm{g})$ was aseptically placed in the center of the plate. In a straight line from the interior to the exterior of the plate, each tested isolate was streaked. K. pneumoniae ATCC 10031 was used as a negative control. The plates were then incubated for $18-24 \mathrm{~h}$ at $37^{\circ} \mathrm{C}$ then examined for a clover leaf-type indentation in the inhibition zone of the carbapenem disc at the intersection of the test organism and E. coli ATCC 8739.

\section{Carbapenem inactivation method (CIM)}

CIM test was performed as previously described [37], with some modifications. Meropenem disc $(10 \mu \mathrm{g})$ was 
incubated for $4 \mathrm{~h}$ in an overnight culture of the tested bacterial isolates. A 0.5 McFarland suspension of $E$. coli ATCC 8739 was swabbed onto Müller-Hinton agar. After incubation, the meropenem disc was placed onto the inoculated Müller-Hinton agar plate and incubated for $18-24 \mathrm{~h}$ at $37^{\circ} \mathrm{C}$. The presence of a clear inhibition zone $(\geq 20 \mathrm{~mm})$ indicated the absence of carbapenemase activity.

\section{Combined disc test (CDT)}

On a Müller-Hinton agar plate inoculated with 1:10 dilution of 0.5 McFarland suspension of E. coli ATCC 8739, imipenem $(10 \mu \mathrm{g})$ and imipenem/EDTA (10/ $930 \mu \mathrm{g}$ ) discs (Oxoid, Basingstoke, United Kingdom) were placed, at a distance of no less than $20 \mathrm{~mm}$ between the centers of the discs. After $18-24 \mathrm{~h}$ of incubation at $37^{\circ} \mathrm{C}$, the diameters of the inhibition zones around the discs were compared [38]. An increased inhibition zone of $\geq 7 \mathrm{~mm}$ with the imipenem/EDTA disc compared to the imipenem disc alone was considered an indication for MBL production.

\section{CarbAcineto NP test}

Two to three colonies of each tested isolate growing on Luria-Bertani (LB) agar plate were picked up and suspended in two Eppendorf tubes (A and $\mathrm{B}$ ) containing $100 \mu \mathrm{L}$ of $5 \mathrm{M} \mathrm{NaCl}$. Both tubes A and B also contained $100 \mu \mathrm{L}$ of revealing solution in addition to $6 \mathrm{mg} / \mathrm{mL}$ imipenem in tube $\mathrm{B}$. The revealing solution comprised of

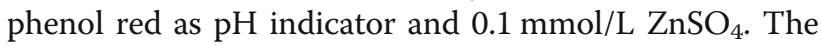
phenol red solution was prepared by adding $2 \mathrm{~mL}$ of a phenol red solution $0.5 \%$ (wt/vol) to $16.6 \mathrm{~mL}$ of distilled water and then adjusting the $\mathrm{pH}$ value to 7.8 by adding $1 \mathrm{~N} \mathrm{NaOH}$. After a maximum incubation time of $2 \mathrm{~h}$ at $37^{\circ} \mathrm{C}$, tubes $\mathrm{A}$ and $\mathrm{B}$ were visually inspected for color change. In tube $\mathrm{B}$, the carbapenemase activity was detected by a color change of phenol red solution (red to yellow/orange) resulting from the hydrolysis of imipenem into a carboxylic derivative, leading to a decrease of the $\mathrm{pH}$ value [39].

\section{Boronic acid disc test}

Ten microliters of 3-aminophenylboronic acid (PBA) dissolved in dimethyl sulfoxide (DMSO) $(40 \mathrm{mg} / \mathrm{mL})$ equivalent to $400 \mu \mathrm{g}$ PBA solution were aseptically dropped onto imipenem and meropenem discs. Treated and untreated imipenem and meropenem discs were also transferred onto Müller-Hinton agar plate inoculated with the tested isolate. In addition, $400 \mu \mathrm{g}$ PBA disc lacking either antibiotic was used on the same plate as a control. After incubation for $18-24 \mathrm{~h}$ at $37^{\circ} \mathrm{C}$, the inhibition zone diameters around the treated imipenem and meropenem discs were compared with the diameters around the plain antibiotic discs. $\mathrm{A} \geq 5 \mathrm{~mm}$ difference in zone diameter was considered as a positive result [40].

\section{Molecular characterization of resistance determinants} For preparation of DNA template, four colonies of each tested clinical isolate were suspended in $200 \mu \mathrm{L}$ sterile deionized water. The suspension was heated at $95^{\circ} \mathrm{C}$ for 30 min and then frozen at $-20^{\circ} \mathrm{C}$ for $30 \mathrm{~min}$. After thawing, the tube was centrifuged at $14,000 \mathrm{rpm}$ for $10 \mathrm{~min}$. The supernatant was then aliquoted and preserved at $-20^{\circ} \mathrm{C}$ for future use [32]. The presence of carbapenemase genes belonging to class A $\left(b l a_{K P C}\right), \mathrm{B}\left(b l a_{I M P}, b l a_{V I M}, b l a_{S I M}\right.$, bla $_{S P M}$, bla $_{G I M}$ and $\left.b l a_{N D M}\right)$ and D (bla oxa-23, bla oxa-40, $b l a_{\text {oxa-51 }}$ and $\left.b l a_{\text {oxa-58 }}\right)$ and insertion sequences: ISAba1, ISAba2 and ISAba3 was investigated in the extracted DNA using PCR, following the conditions detailed in Table 1. All primers are listed in Table 2. Both strands of the NDM amplicons were sequenced using an ABI 3500XL genetic analyzer (Inqaba Biotechnologies, Pretoria, South Africa).

\section{Results \\ Phenotypic detection of carbapenemases}

Seventy four carbapenem-resistant isolates were screened for carbapenemase production by a number of phenotypic methods (MHT, CIM, CDT, CarbAcineto NP test and boronic acid disc test) (Table 3). Regarding MHT, 58 isolates (78.4\%) showed positive result, while the test failed to detect carbapenemase production in the remaining sixteen isolates (21.6\%). Concerning the CIM, 51 isolates $(68.9 \%)$ were carbapenemase producers. Fifty nine of the isolates $(79.7 \%)$ were CDT positive, whereas $42(56.8 \%)$ and $52(70.3 \%)$ isolates showed positive boronic acid disc test in combination with imipenem and meropenem, respectively. CarbAcineto NP test developed positive results with 71 (95.94\%) of the tested isolates. Four isolates (5.4\%) developed the positive result displayed as color change from red to yellow in $<15 \mathrm{~min}$. On the other hand, 67 isolates (90.5\%) turned positive after $2 \mathrm{~h}$ of incubation. Only two isolates $(2.7 \%)$ developed non-interpretable results and one isolate (1.4\%) produced a negative result. However, only 21 isolates $(24.3 \%)$ displayed positive results in all phenotypic tests. It is noteworthy though that at least one of the phenotypic tests was capable of detecting carbapenemase presence in all tested isolates.

\section{Molecular detection of genes encoding different carbapenemases and insertion sequences}

Out of the eleven genes investigated, six genes $\left(b l a_{K P C}\right.$, $b l a_{I M P}, b l a_{S I M}, b l a_{S P M}, b l a_{G I M}$ and $\left.b l a_{O X A-40}\right)$ were not detected in any of the tested isolates. Two metallo- $\beta$ lactamases: $b l a_{V I M}$ and $b l a_{N D M}$ were detected in $74(100 \%)$ and nine (12.1\%) isolates, respectively. Sequencing revealed 
Table 1 PCR conditions of amplification

\begin{tabular}{|c|c|c|c|c|c|c|c|}
\hline \multirow{3}{*}{$\begin{array}{l}\text { Carbapenemase class/Insertion } \\
\text { sequence }\end{array}$} & \multirow[t]{3}{*}{ Gene } & \multicolumn{5}{|c|}{ Thermal cycling conditions } & \multirow{3}{*}{$\begin{array}{l}\text { Master-mix } \\
\text { used }\end{array}$} \\
\hline & & \multirow{2}{*}{$\begin{array}{l}\text { Initial } \\
\text { denaturation }\end{array}$} & \multicolumn{3}{|l|}{30 cycles } & \multirow{2}{*}{$\begin{array}{l}\text { Final } \\
\text { extension }\end{array}$} & \\
\hline & & & Denaturation & Annealing & Extension & & \\
\hline Class D carbapenemases [41] & $\begin{array}{l}\text { bla } \\
\text { ola } \\
\text { oxa-51 } \\
\text { bla }_{\text {oxa }-58} \\
\text { bla }_{\text {oxa }-40}\end{array}$ & $95^{\circ} \mathrm{C} / 1 \mathrm{~min}$ & $95^{\circ} \mathrm{C} / 15 \mathrm{~s}$ & $52^{\circ} \mathrm{C} / 15 \mathrm{~s}$ & $72^{\circ} \mathrm{C} / 10 \mathrm{~s}$ & $72^{\circ} \mathrm{C} / 10 \mathrm{~min}$ & MyTaq $^{\text {TM }}$ HS Mix \\
\hline \multirow[t]{4}{*}{ Class B carbapenemases $[42,43]$} & $b l a_{I M P}$ & $94^{\circ} \mathrm{C} / 5 \mathrm{~min}$ & $94^{\circ} \mathrm{C} / 40 \mathrm{~s}$ & $47^{\circ} \mathrm{C} / 1 \mathrm{~min}$ & $72^{\circ} \mathrm{C} / 2 \mathrm{~min}$ & $72^{\circ} \mathrm{C} / 5 \mathrm{~min}$ & OnePCR ${ }^{\text {TM }}$ \\
\hline & $b l a_{V I M}$ & $94^{\circ} \mathrm{C} / 5 \mathrm{~min}$ & $94^{\circ} \mathrm{C} / 40 \mathrm{~s}$ & $51^{\circ} \mathrm{C} / 1 \mathrm{~min}$ & & & \\
\hline & $\begin{array}{l}\text { bla }_{S M} \\
\text { bla }_{S P M} \\
\text { bla }_{G M}\end{array}$ & $94^{\circ} \mathrm{C} / 5 \mathrm{~min}$ & $94^{\circ} \mathrm{C} / 40 \mathrm{~s}$ & $52^{\circ} \mathrm{C} / 1 \mathrm{~min}$ & & & \\
\hline & $b / a_{N D M}$ & $94^{\circ} \mathrm{C} / 5 \mathrm{~min}$ & $94^{\circ} \mathrm{C} / 40 \mathrm{~s}$ & $54^{\circ} \mathrm{C} / 1 \mathrm{~min}$ & & & \\
\hline Class A carbapenemases [44] & $b l a_{K P C}$ & $94^{\circ} \mathrm{C} / 5 \mathrm{~min}$ & $94^{\circ} \mathrm{C} / 40 \mathrm{~s}$ & $54^{\circ} \mathrm{C} / 1 \mathrm{~min}$ & $72^{\circ} \mathrm{C} / 2 \mathrm{~min}$ & $72^{\circ} \mathrm{C} / 5 \mathrm{~min}$ & OnePCR ${ }^{\mathrm{TM}}$ \\
\hline Insertion sequences [17] & $\begin{array}{l}\text { ISAba1 } \\
\text { ISAba2 } \\
\text { ISAba3 }\end{array}$ & & & & & & \\
\hline
\end{tabular}

Table 2 Oligonucleotide primers sequence and amplicon size

\begin{tabular}{|c|c|c|c|}
\hline Primer name & Nucleotide sequence $\left(5^{\prime} \rightarrow 3^{\prime}\right)$ & No. of bases & Size of the amplicons (bps) \\
\hline OXA-51-F [41] & TAATGCTTTGATCGGCCTTG & 20 & 353 \\
\hline OXA-51-R [41] & TGGATTGCACTTCATCTTGG & 20 & \\
\hline OXA-23-F [41] & GATCGGATTGGAGAACCAGA & 20 & 501 \\
\hline OXA-23-R [41] & АTTCTTGACCGCATTCCAT & 20 & \\
\hline OXA-40-F [41] & GGTTGTTGGCCCCCTTAAA & 19 & 246 \\
\hline OXA-40-R [41] & AGTTGAGCGAAAAGGGGATT & 20 & \\
\hline OXA-58-F [41] & AAGTATTGGGGCTTGTGCTG & 20 & 599 \\
\hline OXA-58-R [41] & CCCCTCTGCGCTCTACATAC & 20 & \\
\hline ISAba1-F [17] & GTGCTITGCGCTCATCATGC & 20 & 430 \\
\hline ISAba1-R [17] & CATGTAAACCAATGCTCACC & 20 & \\
\hline ISAba2-F [17] & AATCCGAGATAGAGCGGTTC & 20 & 1100 \\
\hline ISAba2-R [17] & TGACACATAACCTAGTGCAC & 20 & \\
\hline ISAba3-F [17] & CAATCAAATGTCCAACCTGC & 20 & 403 \\
\hline ISAba3-R [17] & CGTTAACCCCAAACATAAGC & 20 & \\
\hline Pre NDM-F [42] & CACCTCATGTTTGAATTCGCC & 21 & 984 \\
\hline Pre NDM-R [42] & CTCTGTCACATCGAAATCGC & 20 & \\
\hline Imp-F [43] & GGAATAGAGTGGCTTAAYTCTC & 22 & 188 \\
\hline Imp-R [43] & CCAAACYACTASGTTATCT & 19 & \\
\hline Vim-F [43] & GATGGTGTTTGGTCGCATA & 19 & 390 \\
\hline Vim-R [43] & CGAATGCGCAGCACCAG & 17 & \\
\hline Gim-F [43] & TCGACACACCTTGGTCTGAA & 20 & 477 \\
\hline Gim-R [43] & AACTTCCAACTTTGCCATGC & 20 & \\
\hline Spm-F [43] & AAAATCTGGGTACGCAAACG & 20 & 271 \\
\hline Spm-R [43] & ACATTATCCGCTGGAACAGG & 20 & \\
\hline Sim-F [43] & TACAAGGGATTCGGCATCG & 19 & 570 \\
\hline Sim-R [43] & TAATGGCCTGTTCCCATGTG & 20 & \\
\hline KPC-F [44] & GTATCGCCGTCTAGTTCTGC & 20 & 637 \\
\hline KPC-R [44] & GGTCGTGTTTCCCTTTAGCC & 20 & \\
\hline
\end{tabular}


Table 3 Detection of carbapenemases, their encoding genes and insertion sequences among the A. baumannii isolates

\begin{tabular}{|c|c|c|c|c|c|c|c|c|}
\hline \multirow[t]{3}{*}{ Code of isolates } & \multirow{3}{*}{$\begin{array}{l}\text { No. of } \\
\text { isolates }\end{array}$} & \multicolumn{6}{|c|}{ Test result for } & \multirow{3}{*}{$\begin{array}{l}\text { Carbapenemase genes and } \\
\text { insertion sequences }\end{array}$} \\
\hline & & \multirow[t]{2}{*}{$\overline{\mathrm{MHT}}$} & \multirow[t]{2}{*}{ CIM } & \multirow[t]{2}{*}{ CDT } & \multirow{2}{*}{$\begin{array}{l}\text { CarbAcineto } \\
\text { NP }\end{array}$} & \multicolumn{2}{|c|}{ Boronic acid disc } & \\
\hline & & & & & & Imipenem & Meropenem & \\
\hline $\begin{array}{l}\text { A4a, A8a, A10a, A6135a, A14, A27, A41, A71, } \\
\text { A72, A73, A76, A80, A83, A84, A88 }\end{array}$ & 15 & + & + & + & + & + & + & \multirow[t]{26}{*}{ bla $a_{X A-51}, b l a_{O X A-23}, b l a_{V I M}$, ISAbal } \\
\hline $\mathrm{A} 6, \mathrm{~A} 8, \mathrm{~A} 12, \mathrm{A46}, \mathrm{A} 69$ & 5 & + & + & + & + & - & + & \\
\hline $\mathrm{A} 1 \mathrm{a}, \mathrm{A} 14 \mathrm{a}, \mathrm{A} 24, \mathrm{~A} 36$ & 4 & + & - & + & + & - & + & \\
\hline A11a, A25, A37, A68, A91 & 5 & + & + & + & + & - & - & \\
\hline A30, A34, A64, A74 & 4 & - & - & + & + & + & + & \\
\hline $\mathrm{A} 42, \mathrm{~A} 43, \mathrm{~A} 92$ & 3 & + & - & + & + & + & + & \\
\hline $\mathrm{A} 15, \mathrm{~A} 16, \mathrm{~A} 82$ & 3 & + & + & - & + & - & - & \\
\hline$A 13, A 22$ & 2 & + & + & - & + & + & + & \\
\hline A4, A31 & 2 & - & + & + & + & - & + & \\
\hline A7, A39 & 2 & - & + & + & + & + & - & \\
\hline $\mathrm{A} 10, \mathrm{~A} 78$ & 2 & + & - & + & + & - & - & \\
\hline A90 & 1 & + & + & + & + & + & - & \\
\hline A5 & 1 & - & + & + & + & + & + & \\
\hline A18 & 1 & + & - & - & + & + & + & \\
\hline A45 & 1 & + & - & - & + & + & - & \\
\hline A9 & 1 & - & + & - & + & + & + & \\
\hline A33 & 1 & - & - & + & + & + & - & \\
\hline A23 & 1 & + & + & - & + & - & + & \\
\hline $\mathrm{A} 2 \mathrm{a}$ & 1 & - & - & + & + & - & + & \\
\hline A35 & 1 & - & - & + & + & - & - & \\
\hline A26 & 1 & - & - & - & + & + & + & \\
\hline A19 & 1 & + & - & - & + & - & - & \\
\hline $\mathrm{A} 2$ & 1 & + & - & - & - & - & - & \\
\hline A17 & 1 & - & - & - & + & - & - & \\
\hline A87 & 1 & + & + & - & $\mathrm{NI}$ & - & + & \\
\hline A89 & 1 & + & + & + & $\mathrm{NI}$ & + & + & \\
\hline A75 & 1 & + & + & + & + & + & + & \multirow{2}{*}{$\begin{array}{l}\text { bla } a_{O X A-51} \text {, bla } a_{O X A-23}, \text { bla } \\
\text { ISAba2 }\end{array}$} \\
\hline A13a & 1 & - & + & + & + & - & - & \\
\hline $\mathrm{A} 40$ & 1 & + & + & + & + & + & - & \multirow{4}{*}{$\begin{array}{l}\text { bla } a_{O X A-51} \text {, bla } a_{O X A-23}, \text { bla } a_{V I M} \text {, bla } a_{N D M} \text {, } \\
\text { ISAbai }\end{array}$} \\
\hline A59 & 1 & + & + & + & + & - & + & \\
\hline A85 & 1 & + & + & - & + & + & + & \\
\hline $\mathrm{A} 11, \mathrm{~A} 21, \mathrm{~A} 70, \mathrm{~A} 86$ & 4 & + & + & + & + & + & + & \\
\hline A44 & 1 & + & - & + & + & - & + & $\begin{array}{l}\text { bla }_{O X A-51}, \text { bla } \\
\text { ISAba }\end{array}$ \\
\hline A77 & 1 & + & + & + & + & + & + & $\begin{array}{l}\text { bla }_{O X A-51,} \text {, bla } \\
\text { ISAbaI, ISAba3 }\end{array}$ \\
\hline A81 & 1 & + & + & + & + & - & - & $\begin{array}{l}\text { bla }_{O X A-51}, \text { bla } \\
\text { bla }_{V A M}, \text { bla }_{N D M}, \text { ISAbal, ISAba3 }\end{array}$ \\
\hline
\end{tabular}

MHT Modified Hodge Test, CIM Carbapenem Inactivation Method, CDT Combined Disc Test, NI Non-interpretable

that all nine isolates carried $b l a_{N D M-1}$, the sequences were deposited in GenBank (accession numbers: MN395910, MN 395911, MN395912, MN395913, MN395914, MN395915, MN395916, MN395917 and MN395918). Regarding the genes encoding class $\mathrm{D}$ carbapenemases, $b l a_{O X A-51}$ and bla $a_{O X A-23}$ were detected in all tested isolates $(100 \%)$, while $b l a_{\text {OXA-58 }}$ was detected in only one $(1.4 \%)$ isolate: A81. On the other hand, insertion sequence ISAbal was detected in 
all tested isolates $(100 \%)$, while ISAba2 and ISAba3 were detected in two $(2.7 \%)$ and three isolates (4\%), respectively (Table 3).

\section{Discussion}

A. baumannii is becoming a major threat because of the dreadful number of nosocomial infections caused by this pathogen, mostly in ICUs worldwide [45, 46]. In addition, $A$. baumannii has become resistant to several antimicrobial classes due to the irrational use of antibiotics, leading to the predominance of multidrugresistant strains particularly in hospital settings [47]. Moreover, carbapenem resistance among A. baumannii isolates restricts therapeutic options for treatment of such infections which might lead to higher morbidity and mortality rates $[48,49]$. A few previous studies commented on the prevalence of carbapenemases among Egyptian A. baumannii clinical isolates [26, 27, 50-52].

Different mechanisms can contribute to carbapenem resistance, however, the production of MBL and CHDLs remain the most common and prevalent mechanisms among $A$. baumannii isolates [20]. MBLs are especially problematic because their genes are harbored on mobile elements, allowing their easy dissemination among the clinical isolates [49]. On the other hand, CHDLs can be either intrinsic/chromosomal or acquired $\beta$-lactamases [53]. Therefore, detection of carbapenemases among resistant strains is paramount to direct the proper treatment regimen.

This study aimed to phenotypically and molecularly characterize 74 Egyptian $A$. baumannii isolates to identify the different enzymes responsible for carbapenem resistance. Several phenotypic methods, including MHT, CIM, CDT, CarbAcineto NP test and boronic acid disc test were used. Phenotypic detection of carbapenemases has the advantages of low cost, ease of procedure and the absence of complicated or expensive equipment; however, it suffers from poor specificity and sensitivity. Therefore, PCR screening for some genes responsible for carbapenem resistance, as well as some insertion sequences was taken as the gold standard to evaluate the sensitivity of the different phenotypic methods.

Genes encoding for $b l a_{O X A-51}$ and $b l a_{O X A-23}$ belonging to class $\mathrm{D}$ carbapenemases were detected in $100 \%$ of the isolates, whereas bla $a_{O X A-58}$ was detected in only one isolate (A81) obtained in 2010. The bla $_{\text {OXA-51 }}$ is chromosomal and an intrinsic gene of $A$. baumannii species [30]. Among the acquired $\beta$ lactamases are OXA-23-like, OXA-24/40-like and OXA-58-like $\beta$-lactamases [53]. Numerous studies have lately reported that $b l a_{O X A-23}$ is the most prevalent carbapenemase gene identified among CR-AB isolates [53-56]. The prevalence rate of $100 \%$ reported in the current study is in agreement with previous studies [50, 54-57]. A recently published study characterizing $50 \mathrm{~A}$. baumannii isolates from Mansoura, Egypt showed a bla OXA-51, bla OXA-23 prevalence rates of 100 and 94\%, respectively [58]. bla $_{\text {OXA-24/40 }}$ have mostly been found in the Iberian and Asian peninsulas and in other areas in the world $[53-55,59,60]$. Also, bla ${ }_{O X A-40}$ was detected in Egypt with a prevalence rate of $7.5 \%$ [51] and $2.9 \%$ [50]. However, in this study, bla ${ }_{O X A-40}$ was not detected in any of the tested isolates. There are many reports demonstrating the presence of $b l a_{O X A-58}$ in A. baumannii clinical isolates throughout different regions of the world including Algeria, Argentina, Kuwait, the UK, Italy, Turkey, the USA and Spain [57, 60-65]. The bla $a_{O X A-58}$ prevalence reported here $(1.4 \%)$ is lower than previously published rates from Tunisia (4\%), Egypt (9.1\%) [50] and Algeria (14.7\%) [61]. However, bla OXA-58 $_{1}$ was absent in isolates collected in Mansoura, Egypt [58].

Of the genes encoding class B carbapenemases, $b l a_{V I M}$ and $b l a_{N D M}$ were detected in 100 and $12.1 \%$ of the isolates (9 out of 74), respectively. Three of the nine isolates were collected in 2015 showing a prevalence rate of $8.6 \%$ among the new collection whereas the remaining six isolates belonged to the older collection with a prevalence rate of $15.4 \%$. More data are needed, preferably from different regions in the country, before we can safely conclude that the prevalence of $b l a_{N D M}$ is decreasing in Egypt. Benmahmod et al. [58] reported a bla and $b l a_{N D M}$ prevalence rates of 20 and $30 \%$, respectively. The PCR screening results of $b l a_{N D M}$ were validated by sequencing. These results are in accordance with studies reported in China and Saudi Arabia [66-68]. Besides, bla $a_{N D M-1}$ and bla $a_{N D M-2}$ were reported in A. baumannii from Egypt [26, 27] and then disseminated in the entire Middle East [69]. None of the isolates were shown by PCR to carry $b l a_{K P C}$. Similar results were reported by Raible et al. [70], however Benmahmod et al. [58] reported a $b l a_{K P C}$ prevalence rate of $56 \%$. Although bla $a_{S P M-1}, b l a_{G I M}, b l a_{S I M}$ and $b l a_{I M P}$ have been previously detected among Egyptian A. baumannii isolates [52, 56], none of the $A$. baumannii isolates in the current study harbored any of these genes.

Comparing the results of the phenotypic tests to the results of the molecular detection of carbapenemases showed that the sensitivity of MHT, CIM, CDT, CarbAcineto NP, boronic acid with imipenem and meropenem was $78.4,68.9,79.7,95.9,56.8$ and $70.3 \%$, respectively. In the CarbAcineto NP test, four isolates carrying $b l a_{O X A-51}$, $b l a_{O X A-23}, b l a_{V I M}$, including isolate no. A81 that additionally carried $b l a_{O X A-58}$ developed the positive result in less than 15 min which could be attributed to the activity of the enzymes in these isolates. The false negative result recorded with A2 that carried bla $a_{V I M}, b l a_{O X A-51}$ 
and bla $_{O X A-23}$ could be explained by the low zinc concentration in the culture medium [71] or due to very low carbapenemase activity in the tested isolate [72]. These findings agree with the previously reported high sensitivity of CarbAcineto NP in carbapenemase detection among Acinetobacter spp. [39].

The sensitivity of MHT in the current study is also in agreement with previously published reports in which MHT was able to detect carbapenemase production in $83.3,71$ and $73 \%$ of the screened carbapenem-resistant isolates [73-75]. According to CLSI 2018, MHT is no longer recommended as a phenotypic test for carbapenemase detection, presumably because of the poor specificity of the test when detecting someextended spectrum $\beta$ lactamase production occurring with porin loss [76]. However, in the present study, all isolates shown by MHT to be carbapenemase producers also carried one or more carbapenemase genes as shown by PCR. The failure of CIM to detect carbapenemase production in 23 isolates could be due to the short incubation period of the meropenem disc relative to other studies that recommended six hours of incubation particularly with low level carbapenemase activity [77]. In the current study, CDT was capable of detecting the carbapenemases in $79.7 \%$ of the cases which is lower than the detection rate reported by Pandya et al. [78] (96.3\%), Irfan et al. [79] (96.6\%) and Anwar et al. [73] (95.4\%). Boronic acid disc test has been reported to be an accurate phenotypic test for the detection of KPC carbapenemases [80-83]. However, the data concerning the application of the test for detection of other carbapenemases is unsatisfactory [84]. In the present work, no $b l a_{K P C}$ was detected.

Although only 21 isolates showed positive tests allover, all nine isolates that were shown to carry NDM by PCR also gave positive test in MHT, CIM and CarbAcineto $\mathrm{NP}$ making the sensitivity of these tests to detect MBL $100 \%$. On the other hand, CDT failed to detect NDM in one isolate: A85 and boronic acid disc test with imipenem and meropenem failed to detect NDM in 2 isolates each: A59 and A81 and A40 and A81, respectively. It is noteworthy that A81 was the only isolate shown to carry bla $a_{\text {OXA-58. }}$

When present upstream to CHDL encoding genes, insertion sequences may increase the production of $\beta$ lactamases $[65,85]$. In the current study, the prevalence of ISAba1, ISAba2 and ISAba3 was 100, 2.7 and $4.1 \%$, respectively. The prevalence of different insertion sequences in A. baumannii clinical isolates from Saudi Arabia was in agreement with the findings in the current study [68].

\section{Conclusions}

With the exception of CarbAcineto NP that showed superior sensitivity approaching PCR results, a combination of phenotypic tests, including MHT, CIM, CDT and boronic acid disc tests seems essential for the conclusive detection of carbapenemases. NDM prevalence levels detected here are smaller than previously reported from other parts of the country which suggests the need for larger screening encompassing different Egyptian governorates to determine the exact prevalence rate. However, OXA-23 and VIM prevalence rates remain equally high.

\section{Abbreviations}

ATCC: American Type Culture Collection; bp: Base pair; CDT: Combined disc test; CHDL: Carbapenem-hydrolyzing class D $\beta$-lactamases; CIM: Carbapenem inactivation method; CR-AB: Carbapenem-resistant Acinetobacter baumannii; DMSO: Dimethyl sulfoxide; DNA: Deoxyribonucleic acid; EDTA: Ethylene diamine tetraacetic acid; ESKAPE: Enterococcus faecium, Staphylococcus aureus, Klebsiella pneumoniae, Acinetobacter baumannii, Pseudomonas aeruginosa and Enterobacter species; ICU: Intensive care unit; IMP: Imipenemase; KPC: Klebsiella pneumoniae carbapenemase; LB: LuriaBertani; MALDI-TOF MS: Matrix Assisted Laser Desorption Ionization - Time of Flight Mass Spectrometry; MBL: Metallo- $\beta$-lactamase; Mg/ml: Milligram per milliliter; MHT: Modified Hodge test; MIC: Minimum inhibitory concentration; Min: Minute; NDM: New Delhi metallo-- $\beta$-lactamase; OXA: Oxacillinase; PBA: 3aminophenylboronic acid; PCR: Polymerase chain reaction; Rpm: Round per minute; Sec: Second; SIM: Seoul Imipenemase; VIM: Verona integron-encoded metallo- $\beta$-lactamase; $\mu \mathrm{g}$ : Microgram

\section{Acknowledgements}

The authors would like to thank Dr. Mervat Kassem and Sylvia Danial for their help in isolate collection.

\section{Authors' contributions}

AT performed the experiments, participated in data analysis and contributed to manuscript writing. AA designed the study, analyzed the results and actively participated in manuscript writing. EA designed the study and critically reviewed the manuscript. All authors revised the manuscript and approved the final form.

\section{Funding}

This work was supported by the Egyptian Science and Technology Development Fund (STDF) [grant number 25368]. The funding body had no role in the study design and collection, analysis and interpretation of data or in the writing of the manuscript.

\section{Availability of data and materials}

The datasets used and/or analyzed during the current study are available from the corresponding author on reasonable request.

Ethics approval and consent to participate

Not applicable.

\section{Consent for publication}

Not applicable.

\section{Competing interests}

The authors declare that they have no competing interests.

Received: 10 May 2019 Accepted: 21 September 2019

Published online: 20 November 2019

\section{References}

1. Howard A, O'Donoghue M, Feeney A, Sleator RD. Acinetobacter baumannii: an emerging opportunistic pathogen. Virulence. 2012;3(3):243-50.

2. Fernández J, Acevedo J, Castro M, Garcia O, de Lope CR, Roca D, et al. Prevalence and risk factors of infections by multiresistant bacteria in cirrhosis: a prospective study. Hepatology. 2012;55(5):1551-61.

3. McConnell MJ, Actis L, Pachón J. Acinetobacter baumannii: human infections, factors contributing to pathogenesis and animal models. FEMS Microbiol Rev. 2013;37(2):130-55. 
4. Dijkshoorn L, Nemec A, Seifert H. An increasing threat in hospitals: multidrug-resistant Acinetobacter baumannii. Nat Rev Microbiol. 2007;5(12): 939-51

5. Villegas MV, Hartstein Al. Acinetobacter outbreaks, 1977-2000. Infect Control Hosp Epidemiol. 2003 Apr;24(4):284-95.

6. Alsan M, Klompas M. Acinetobacter baumannii: an emerging and important pathogen. J Clin Outcomes Manag. 2010;17(8):363-9.

7. Bergogne-Berezin E, Towner KJ. Acinetobacter spp. as nosocomial pathogens: microbiological, clinical, and epidemiological features. Clin Microbiol Rev. 1996;9(2):148-65.

8. Rice LB. Federal funding for the study of antimicrobial resistance in nosocomial pathogens: no ESKAPE. J Infect Dis. 2008 Apr 15;197(8):1079-81.

9. De Rosa FG, Corcione S, Pagani N, Di Perri G. From ESKAPE to ESCAPE, from KPC to CCC. Clin Infect Dis. 2015;60(8):1289-90.

10. Chang W, Lu C, Huang C, Chuang Y. Community-acquired Acinetobacter meningitis in adults. Infection. 2000;28(6):395-7.

11. Falagas M, Karveli E, Kelesidis I, Kelesidis T. Community-acquired Acinetobacter infections. Eur J Clin Microbiol Infect Dis. 2007;26(12):857-68.

12. Héritier C, Poirel L, Fournier P-E, Claverie J-M, Raoult D, Nordmann P. Characterization of the naturally occurring oxacillinase of Acinetobacter baumannii. Antimicrob Agents Chemother. 2005:49(10):4174-9.

13. Brown $S$, Young $H$, Amyes $S$. Characterisation of OXA-51, a novel class $D$ carbapenemase found in genetically unrelated clinical strains of Acinetobacter baumannii from Argentina. Clin Microbiol Infect. 2005;11(1):15-23.

14. Almasaudi SB. Acinetobacter spp. as nosocomial pathogens: epidemiology and resistance features. Saudi J Biol Sci. 2018;25(3):586-96.

15. Meletis G. Carbapenem resistance: overview of the problem and future perspectives. Ther Adv Infect Dis. 2016 Feb;3(1):15-21.

16. Queenan AM, Bush K. Carbapenemases: the versatile beta-lactamases. Clin Microbiol Rev. 2007:20(3):440-58.

17. Poirel L, Nordmann P. Carbapenem resistance in Acinetobacter baumannii: mechanisms and epidemiology. Clin Microbiol Infect. 2006 Sep;12(9):826-36.

18. Gordon NC, Wareham DW. Multidrug-resistant Acinetobacter baumannii: mechanisms of virulence and resistance. Int J Antimicrob Agents. 2010;35(3):219-26.

19. Kim Y, Kim S, Kim Y, Hong K, Wie S, Park Y, et al. Carbapenem-resistant Acinetobacter baumannii: diversity of resistant mechanisms and risk factors for infection. Epidemiol Infect. 2012;140(1):137-45.

20. Lin MF, Lan CY. Antimicrobial resistance in Acinetobacter baumannii: from bench to bedside. World J Clin Cases. 2014;2(12):787-814

21. Paton R, Miles RS, Hood J, Amyes SG, Miles RS, Amyes SG. ARI 1: betalactamase-mediated imipenem resistance in Acinetobacter baumannii. Int $J$ Antimicrob Agents. 1993 Feb;2(2):81-7.

22. Scaife W, Young HK, Paton RH, Amyes SG. Transferable imipenem-resistance in Acinetobacter species from a clinical source. J Antimicrob Chemother. 1995 Sep;36(3):585-6.

23. Jeon JH, Lee JH, Lee JJ, Park KS, Karim AM, Lee CR, et al. Structural basis for Carbapenem-hydrolyzing mechanisms of Carbapenemases conferring antibiotic resistance. Int J Mol Sci. 2015;16(5):9654-92.

24. Thomson KS. Extended-spectrum- $\beta$-lactamase, AmpC, and carbapenemase issues. J Clin Microbiol. 2010;48(4):1019-25.

25. Bonnin R, Poirel L, Naas T, Pirs M, Seme K, Schrenzel J, et al. Dissemination of New Delhi metallo- $\beta$-lactamase-1-producing Acinetobacter baumannii in Europe Clin Microbiol Infect. 2012;18(9):E362-E5.

26. Hrabák J, Štolbová M, Študentová V, Fridrichová M, Chudáčková E, Zemlickova H. NDM-1 producing Acinetobacter baumannii isolated from a patient repatriated to the Czech Republic from Egypt, July 2011. Eurosurveillance. 2012;17(7):1-3.

27. Kaase M, Nordmann P, Wichelhaus TA, Gatermann SG, Bonnin RA, Poirel L. NDM-2 carbapenemase in Acinetobacter baumannii from Egypt. J Antimicrob Chemother. 2011;66(6):1260-2.

28. Bush K, Jacoby GA, Medeiros AA. A functional classification scheme for beta-lactamases and its correlation with molecular structure. Antimicrob Agents Chemother. 1995;39(6):1211-33.

29. Poirel L, Naas T, Nordmann P. Diversity, epidemiology, and genetics of class D B-lactamases. Antimicrob Agents Chemother. 2010;54(1):24-38.

30. Turton JF, Ward ME, Woodford N, Kaufmann ME, Pike R, Livermore DM, et al. The role of ISAba1 in expression of OXA carbapenemase genes in Acinetobacter baumannii. FEMS Microbiol Lett. 2006;258(1):72-7.

31. Constantiniu S, Romaniuc A, lancu LS, Filimon R, Taraşi I. Cultural and biochemical characteristics of Acinetobacter spp strains isolated from hospital units. J Prev Med. 2004;12(3-4):35-42.
32. Sambrook J, Fritsch EF, Maniatis T. Molecular cloning: a laboratory manual. 2nd ed. New York: Cold spring harbor laboratory press; 1989.

33. De Carolis E, Vella A, Vaccaro L, Torelli R, Spanu T, Fiori B, et al. Application of MALDI-TOF mass spectrometry in clinical diagnostic microbiology. J Infect Dev Ctries. 2014;8(9):1081-8.

34. Singhal N, Kumar M, Kanaujia PK, Virdi JS. MALDI-TOF mass spectrometry: an emerging technology for microbial identification and diagnosis. Front Microbiol. 2015;6:791.

35. CLSI. M100-S28 performance standards for antimicrobial susceptibility testing. 2018.

36. Amjad A, Mirza I, Abbasi S, Farwa U, Malik N, Zia F. Modified Hodge test: a simple and effective test for detection of carbapenemase production. Iran J Microbiol. 2011:3(4):189-93.

37. van der Zwaluw K, de Haan A, Pluister GN, Bootsma HJ, de Neeling AJ, Schouls LM. The carbapenem inactivation method (CIM), a simple and lowcost alternative for the Carba NP test to assess phenotypic carbapenemase activity in gram-negative rods. PLoS One. 2015:10(3):1-13.

38. Yong D, Lee K, Yum JH, Shin HB, Rossolini GM, Chong Y. Imipenem-EDTA disk method for differentiation of metallo- $\beta$-lactamase-producing clinical isolates of Pseudomonas spp. and Acinetobacter spp. J Clin Microbiol. 2002; 40(10):3798-801.

39. Dortet L, Poirel L, Errera C, Nordmann P. CarbAcineto NP test for rapid detection of carbapenemase-producing Acinetobacter spp. J Clin Microbiol. 2014 Jul;:52(7):2359-64

40. Tsakris A, Kristo I, Poulou A, Themeli-Digalaki K, Ikonomidis A, Petropoulou $D$, et al. Evaluation of boronic acid disk tests for differentiating KPCpossessing Klebsiella pneumoniae isolates in the clinical laboratory. J Clin Microbiol. 2009:47(2):362-7.

41. Woodford N, Ellington MJ, Coelho JM, Turton JF, Ward ME, Brown S, et al. Multiplex PCR for genes encoding prevalent OXA carbapenemases in Acinetobacter spp. Int J Antimicrob Agents. 2006;27(4):351-3.

42. Poirel L, Hombrouck-Alet C, Freneaux C, Bernabeu S, Nordmann P. Global spread of New Delhi metallo-beta-lactamase 1. Lancet Infect Dis. 2010; 10(12):832.

43. Ellington MJ, Kistler J, Livermore DM, Woodford N. Multiplex PCR for rapid detection of genes encoding acquired metallo- $\beta$-lactamases. J Antimicrob Chemother. 2006;59(2):321-2.

44. Hong SS, Kim K, Huh JY, Jung B, Kang MS, Hong SG. Multiplex PCR for rapid detection of genes encoding class a carbapenemases. Ann Lab Med. 2012; 32(5):359-61.

45. Garnacho-Montero J, Amaya-Villar R. Multiresistant Acinetobacter baumannii infections: epidemiology and management. Curr Opin Infect Dis. 2010;23(4): $332-9$.

46. Vincent J-L, Rello J, Marshall J, Silva E, Anzueto A, Martin CD, et al. International study of the prevalence and outcomes of infection in intensive care units. JAMA. 2009;302(21):2323-9.

47. Lee K, Yong D, Jeong SH, Chong Y. Multidrug-resistant Acinetobacter spp.: increasingly problematic nosocomial pathogens. Yonsei Med J. 2011;52(6): 879-91.

48. Richet HM, Mohammed J, McDonald LC, Jarvis WR. Building communication networks: international network for the study and prevention of emerging antimicrobial resistance. Emerg Infect Dis. 2001 Mar-Apr;7(2):319-22.

49. Fattouh $\mathrm{M}, \mathrm{El}$-din AN. Emergence of carbapenemresistant Acinetobacter baumannii in the intensive care unit in Sohag University hospital, Egypt. Int J Curr Microbiol App Sci. 2014:3(4):732-44.

50. Al-Hassan L, El Mehallawy H, Amyes S. Diversity in Acinetobacter baumannii isolates from paediatric cancer patients in Egypt. Clin Microbiol Infect. 2013; 19(11):1082-8.

51. Al-Agamy MH, Khalaf NG, Tawfick MM, Shibl AM, El Kholy A. Molecular characterization of carbapenem-insensitive Acinetobacter baumannii in Egypt. Int J Infect Dis. 2014;22:49-54.

52. Mohamed NM, Raafat D. Phenotypic and genotypic detection of Metallo-betalactamases in Imipenem-resistant Acinetobacter baumannii isolated from a tertiary Hospital in Alexandria, Egypt. Res J Microbiol. 2011:6(10):750-60.

53. Abbott I, Cerqueira GM, Bhuiyan S, Peleg AY. Carbapenem resistance in Acinetobacter baumannii: laboratory challenges, mechanistic insights and therapeutic strategies. Expert Rev Anti-Infect Ther. 2013;11(4):395-409.

54. Al-Agamy MH, Shibl AM, Ali MS, Khubnani $H$, Radwan $H$ H, Livermore DM. Distribution of $\beta$-lactamases in carbapenem-non-susceptible Acinetobacter baumannii in Riyadh, Saudi Arabia. J Glob Antimicrob Resist. 2014;2(1):17-21. 
55. Cicek AC, Saral A, Iraz M, Ceylan A, Duzgun A, Peleg A, et al. OXA-and GES type $\beta$-lactamases predominate in extensively drug-resistant Acinetobacter baumannii isolates from a Turkish University hospital. Clin Microbiol Infect. 2014:20(5):410-5.

56. Fouad M, Attia AS, Tawakkol WM, Hashem AM. Emergence of carbapenemresistant Acinetobacter baumannii harboring the OXA-23 carbapenemase in intensive care units of Egyptian hospitals. Int J Infect Dis. 2013;17(12):e1252-e4.

57. Mathlouthi N, Ben Lamine Y, Somai R, Bouhalila-Besbes S, Bakour S, Rolain J$\mathrm{M}$, et al. Incidence of OXA-23 and OXA-58 carbapenemases coexpressed in clinical isolates of Acinetobacter baumannii in Tunisia. Microb Drug Resist. 2018;24(2):136-41.

58. Benmahmod AB, Said HS, Ibrahim RH. Prevalence and mechanisms of carbapenem resistance among Acinetobacter baumannii clinical isolates in Egypt. Microb Drug Resist. 2018;25(4):480-8.

59. Wisplinghoff $H$, Paulus $T$, Lugenheim M, Stefanik D, Higgins PG, Edmond $\mathrm{MB}$, et al. Nosocomial bloodstream infections due to Acinetobacter baumannii, Acinetobacter pittii and Acinetobacter nosocomialis in the United States. J Inf Secur. 2012;64(3):282-90.

60. Acosta J, Merino M, Viedma E, Poza M, Sanz F, Otero JR, et al. Multidrugresistant Acinetobacter baumannii harboring OXA-24 carbapenemase, Spain. Emerg Infect Dis. 2011;17(6):1064-7.

61. Touati M, Diene SM, Racherache A, Dekhil M, Djahoudi A, Rolain J-M. Emergence of bla $a_{O X A-23}$ and $b l a_{O X A-58}$ carbapenemase-encoding genes in multidrug-resistant Acinetobacter baumannii isolates from University Hospital of Annaba, Algeria. Int J Antimicrob Agents. 2012;40(1):89-91.

62. Coelho J, Woodford N, Afzal-Shah M, Livermore D. Occurrence of OXA-58like carbapenemases in Acinetobacter spp. collected over 10 years in three continents. Antimicrob Agents Chemother. 2006;50(2):756-8.

63. Migliavacca R, Espinal P, Principe L, Drago M, Fugazza G, Roca I, et al. Characterization of resistance mechanisms and genetic relatedness of carbapenem-resistant Acinetobacter baumannii isolated from blood, Italy. Diagn Microbiol Infect Dis. 2013;75(2):180-6.

64. Metan G, Sariguzel F, Sumerkan B, van der Reijden T, Dijkshoorn L. Clonal diversity and high prevalence of OXA-58 among Acinetobacter baumannii isolates from blood cultures in a tertiary care Centre in Turkey. Infect Genet Evol. 2013:14:92-7.

65. Lopes B, Al-Hassan L, Amyes S. ISAba825 controls the expression of the chromosomal bla OXA-51-like and the plasmid borne bla OXA-58 gene in clinical isolates of Acinetobacter baumannii isolated from the USA. Clin Microbiol Infect. 2012;18(11):E446-E51.

66. Al-Sultan AA, Evans BA, Aboulmagd E, Al-Qahtani AA, Bohol MF, Al-Ahdal $M N$, et al. Dissemination of multiple carbapenem-resistant clones of Acinetobacter baumannii in the Eastern District of Saudi Arabia. Front Microbiol. 2015;6:634

67. Chen Y, Zhou Z, Jiang Y, Yu Y. Emergence of NDM-1-producing Acinetobacter baumannii in China. J Antimicrob Chemother. 2011;66(6):1255-9.

68. Alsultan AA, Aboulmagd E, Evans BA, Amyes SG. Clonal diversity of Acinetobacter baumannii from diabetic patients in Saudi Arabian hospitals. J Med Microbiol. 2014;63(11):1460-6.

69. Espinal P, Poirel L, Carmeli Y, Kaase M, Pal T, Nordmann P, et al. Spread of NDM-2-producing Acinetobacter baumannii in the Middle East. J Antimicrob Chemother. 2013;68(8):1928-30

70. Raible KM, Sen B, Law N, Bias TE, Emery CL, Ehrlich GD, et al. Molecular characterization of $\beta$-lactamase genes in clinical isolates of carbapenemresistant Acinetobacter baumannii. Ann Clin Microbiol Antimicrob. 2017; 16(1):1-10.

71. Dortet L, Bréchard L, Poirel L, Nordmann P. Impact of the isolation medium for detection of carbapenemase-producing Enterobacteriaceae using an updated version of the Carba NP test. J Med Microbiol. 2014;63(5):772-6.

72. Literacka E, Herda M, Baraniak A, Żabicka D, Hryniewicz W, Skoczyńska A et al. Evaluation of the Carba NP test for carbapenemase detection in Enterobacteriaceae, Pseudomonas spp. and Acinetobacter spp., and its practical use in the routine work of a national reference laboratory for susceptibility testing. Eur J Clin Microbiol Infect Dis. 2017:36(11):2281-7.

73. Anwar M, Ejaz H, Zafar A, Hamid H. Phenotypic detection of metallo-betalactamases in carbapenem resistant Acinetobacter baumannii isolated from pediatric patients in Pakistan. J Pathog. 2016;2016:1-6.

74. Kumar AV, Pillai VS, Dinesh KR, Karim S. The phenotypic detection of Carbapenemase in meropenem resistant Acinetobacter calcoaceticus baumannii complex in a tertiary care hospital in South India. J Clin Diagn Res. 2011;5(2):223-6.
75. Lee K, Lim Y, Yong D, Yum J, Chong Y. Evaluation of the Hodge test and the imipenem-EDTA double-disk synergy test for differentiating metallo- $\beta$ lactamase-producing isolates of Pseudomonas spp. and Acinetobacter spp. J Clin Microbiol. 2003:41(10):4623-9.

76. Carvalhaes CG, Picao RC, Nicoletti AG, Xavier DE, Gales AC. Cloverleaf test (modified Hodge test) for detecting carbapenemase production in Klebsiella pneumoniae: be aware of false positive results. J Antimicrob Chemother. 2010 Feb;65(2):249-51.

77. Aktaş E, Malkoçoğlu G, Otlu B, Çopur Çiçek A, Külah C, Cömert F, et al. Evaluation of the carbapenem inactivation method for detection of carbapenemase-producing gram-negative bacteria in comparison with the Rapidec Carba NP. Microb Drug Resist. 2017;23(4):457-61.

78. Pandya NP, Prajapati SB, Mehta SJ, Kikani KM, Joshi PJ. Evaluation of various methods for detection of metallo $\beta$-lactamase (MBL) production in gram negative bacilli. Int J Biol Med Res. 2011:2(3):775-7.

79. Irfan S, Zafar A, Guhar D, Ahsan T, Hasan R. Metallo-beta-lactamaseproducing clinical isolates of Acinetobacter species and Pseudomonas aeruginosa from intensive care unit patients of a tertiary care hospital. Indian J Med Microbiol. 2008 Jul-Sep;26(3):243-5.

80. Ribeiro VB, Linhares AR, Zavascki AP, Barth AL. Performance of quantification of modified Hodge test: an evaluation with Klebsiella pneumoniae carbapenemase-producing Enterobacteriaceae isolates. Biomed Res Int. 2014;2014:1-6.

81. Hung K-H, Yan J-J, Lu J-J, Chen H-M, Wu J-J. Characterization of the modified Hodge test-positive isolates of Enterobacteriaceae in Taiwan. J Microbiol Immunol Infect. 2013:46(1):35-40.

82. Van Dijk K, Voets G, Scharringa J, Voskuil S, Fluit A, Rottier W, et al. A disc diffusion assay for detection of class a, B and OXA-48 carbapenemases in Enterobacteriaceae using phenyl boronic acid, dipicolinic acid and temocillin. Clin Microbiol Infect. 2014;20(4):345-9.

83. Anderson KF, Lonsway DR, Rasheed JK, Biddle J, Jensen B, McDougal LK, et al. Evaluation of methods to identify the Klebsiella pneumoniae carbapenemase in Enterobacteriaceae. J Clin Microbiol. 2007:45(8):2723-5.

84. Arnold RS, Thom KA, Sharma S, Phillips M, Kristie Johnson J, Morgan DJ. Emergence of Klebsiella pneumoniae carbapenemase-producing bacteria. South Med J. 2011 Jan;104(1):40-5.

85. Segal H, Jacobson R, Garny S, Bamford C, Gay EB. Extended 10 promoter in ISAba-1 upstream of bla OXA-23 from Acinetobacter baumannii. Antimicrob Agents Chemother. 2007;51(8):3040-1.

\section{Publisher's Note}

Springer Nature remains neutral with regard to jurisdictional claims in published maps and institutional affiliations.

Ready to submit your research? Choose BMC and benefit from:

- fast, convenient online submission

- thorough peer review by experienced researchers in your field

- rapid publication on acceptance

- support for research data, including large and complex data types

- gold Open Access which fosters wider collaboration and increased citations

- maximum visibility for your research: over $100 \mathrm{M}$ website views per year

At $\mathrm{BMC}$, research is always in progress.

Learn more biomedcentral.com/submissions 